\title{
The space-flight environment: the International Space Station and beyond
}

\author{
Robert Thirsk MDCM SM, Andre Kuipers MD, Chiaki Mukai MD PhD, David Williams MDCM MSc
}

Published at www.cmaj.ca on the day the Soyuz rocket left for the International Space Station.

$\mathrm{H}$ uman space exploration is dependent on robust spacecraft design and sophisticated life-support technologies, both of which are critical for working in the hostile space environment. This article focuses on the specific challenges of the space environment. In an upcoming issue, a Dispatch from Space provides a personal look at space travel, and 2 other articles address the acclimation necessary for people to travel and live in space and the technological advances that can be applied to health care on earth.

The early space program progressed from suborbital missions lasting minutes to orbital flights lasting days, demonstrating that people can both survive and work in space. Almost 50 years have elapsed since those initial flights, with remarkable progress in extending the duration of missions and the complexity of the objectives. The International Space Station circles the earth at an altitude of more than $300 \mathrm{~km}$ in an environment characterized by high vacuum, microgravity, extremes of temperature, meteoroids, space debris, ionospheric plasma, and ultraviolet and ionizing radiation. The development of new technologies to send people farther in space and keep them there longer is critical to the future of human space exploration.

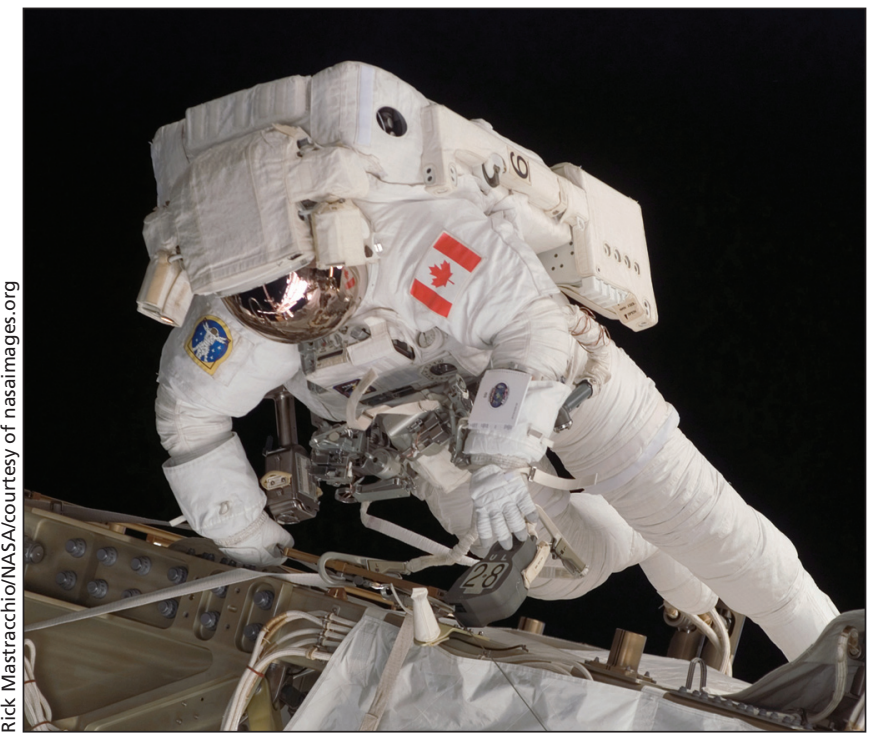

During the first spacewalk of NASA mission STS-118, Canadian astronaut Dave Williams worked on the P6 module of the International Space Station.

\section{Key points}

- Because of the harsh environment in space, astronauts are at risk for both short- and long-term health risks.

- The 2 major challenges associated with spaceflight are radiation effects and the physiologic consequences of a microgravity environment.

- Many of the immediate risks (decompression, thermal injury, arcing injuries) are mitigated by the design of the spacecraft and spacesuits.

- The biologic effects of long-term exposure to space radiation are unclear but may include the development of cataracts and cancer.

There are different definitions for the boundary to space. National Aeronautics and Space Administration (NASA) uses flight above $80 \mathrm{~km}$ to designate individuals as astronauts, while the Fédération Aéronautique Internationale uses the $100 \mathrm{~km}$ Karman line as the internationally accepted boundary to space. Beyond this altitude, aerodynamic flight is not possible, and spacecraft must travel faster than orbital velocity to manoeuvre and remain in orbit.

\section{Evidence}

Only about 350 people have flown in space over the last 4 decades, making it difficult to develop higher levels of clinical evidence to assess the efficacy of interventions in space medicine. Case series and descriptive studies represent the majority of the published literature in the field. ${ }^{1}$ A review of technical and special publications from NASA and peerreviewed literature was undertaken to complement our experiences. Each of us has experienced space first-hand, and, as a group, we have logged 2000 hours in space. One of the authors (D.W.) holds the Canadian record for spacewalking, with over 17 hours spent working outside of the space station.

\section{Environmental characteristics}

Research programs into bioastronautics and longitudinal studies of astronaut health have amassed considerable data that can help us to understand the environmental character-

From the Canadian Space Agency (Thirsk); the European Space Agency Astronaut Corps (Kuipers); the Japan Aerospace Exploration Agency (Mukai); and the Department of Surgery (Williams), McMaster University, Hamilton, Ont. 
istics of orbital flight that present the greatest health and safety concerns to astronauts. The environmental factors of concern during long missions aboard the International Space Station are summarized in Table 1, along with current mitigation measures developed by the Multilateral Medical Policy Board.

\section{Temperature extremes}

Spacecraft in low orbit of the earth travel at Mach 25, or about $8 \mathrm{~km}$ per second. These spacecraft orbit the earth once every 90 minutes. The crew controls the temperature in the crew compartment of the space shuttle and modules of the International Space Station, with an average temperature between 21 and $23^{\circ} \mathrm{C}$. Much greater extremes occur outside the spacecraft. When on the sun-lit side of the earth, the temperature on the spacecraft or space station can reach over $100^{\circ} \mathrm{C}$. Forty-five minutes later, during a night pass through earth's dark shadow, temperatures can plunge to $-100^{\circ} \mathrm{C} .^{2}$
During spacewalks, the personal life-support system of the spacesuit provides active cooling to dissipate the heat generated by high-metabolic workloads. A manually controlled thermostat is used to control active cooling and regulate the temperature in the suit. Heating the suit is a passive process resulting from accumulated body heat in the absence of active cooling. Manually activated electric heaters in astronauts' gloves may be used when the touch temperatures fall below $-20^{\circ} \mathrm{C}$. Thermal mittens can also be used to provide insulation from high touch temperatures.

During a spacewalk, it is easy to become focused on a task and lose awareness of an impending dusk or dawn, until surrounded by darkness or brilliant sunlight. Temperature is often the first cue that these transitions are imminent.

\section{Circadian dyssynchrony}

The light-dark transition that occurs every 45 minutes results in changes in the thermal properties of the spacecraft and in power generated from solar arrays. This transition is of interest as a po-

Table 1: Characteristics of the space environment in the low earth orbit and measures to reduce the impact on crew health and safety

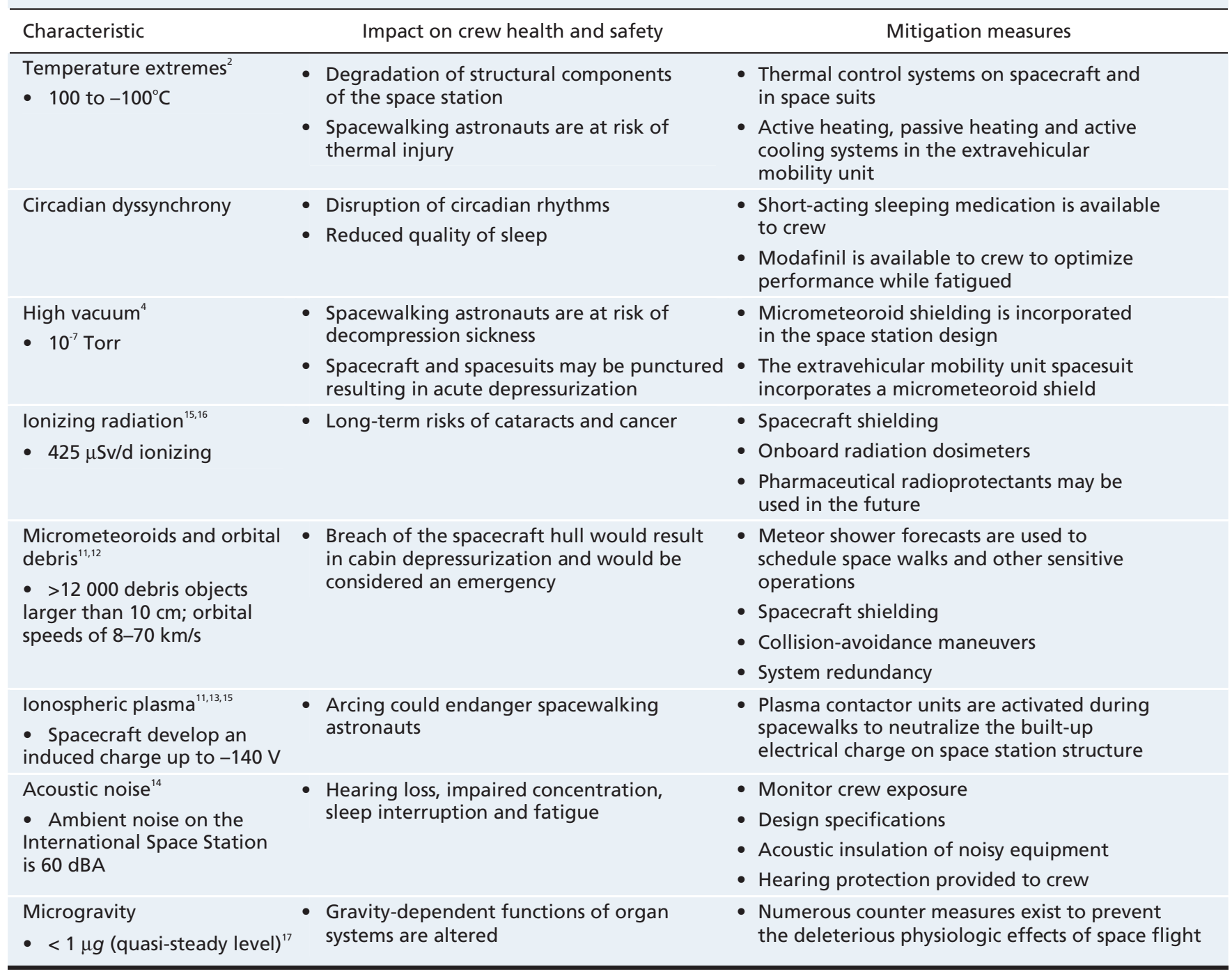




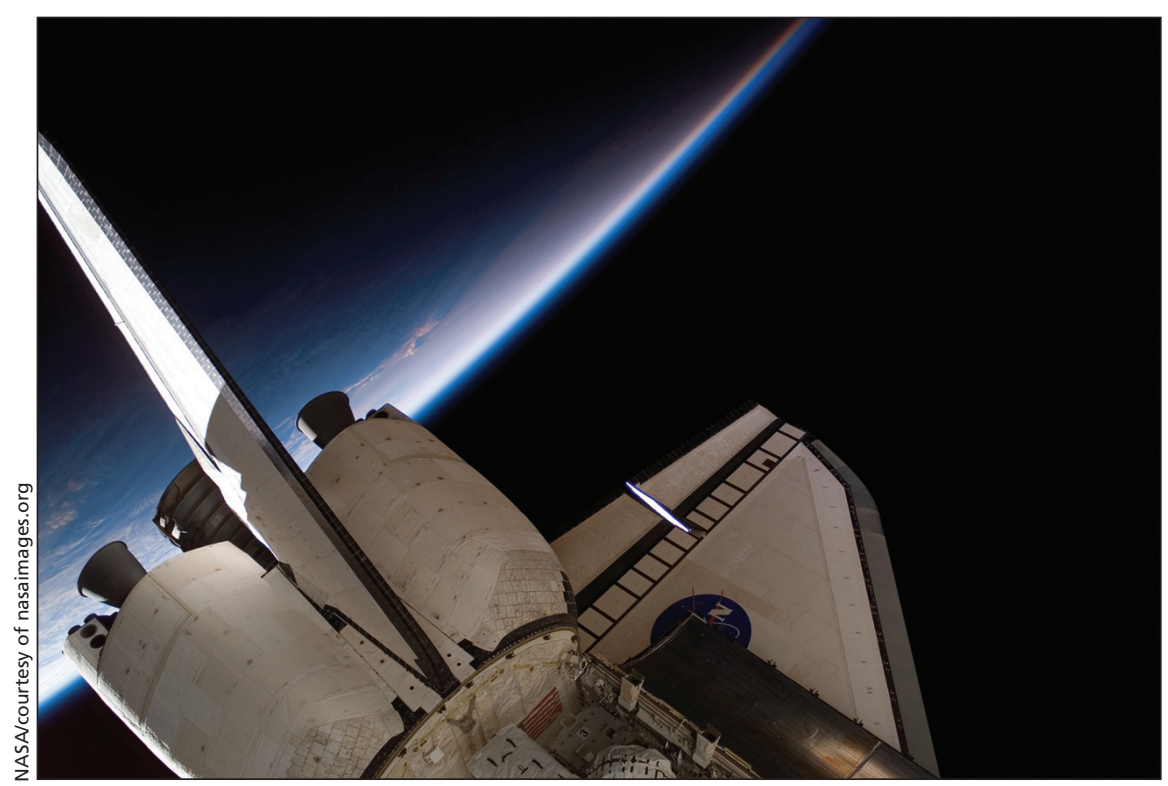

Space Shuttle Endeavour's orbital manoeuvring system pods and vertical stabilizer are shown in this image while the shuttle was docked on the International Space Station during mission STS-118.

\section{lonizing radiation}

At an orbital altitude of $350 \mathrm{~km}$, the International Space Station is above the earth's magnetosphere. This results in exposure of astronauts to higher fluxes of ionizing radiation. The primary radiation sources are galactic cosmic rays (energetic particles from outside our solar system), particles trapped in the earth's magnetic field (the Van Allen Belts) and solar energetic particle events (solar flares). ${ }^{5,6}$ High-energy protons and heavy ions emanate from the Sun and elsewhere in the cosmos. Even higher energy secondary particles (protons, neutrons and heavy ions) are produced when the incoming radiation strikes the spacecraft hull.

The $52^{\circ}$ orbital inclination of the International Space Station causes it to pass through the South Atlantic Anomaly daily. This region, located east of Argentina, is characterized by an anomalous perturbation in the earth's geomagnetic field with trapped energetic particles

tential source of circadian dyssynchrony.

The irregular light pattern caused by the 16 daily sunsets and sunrises may disrupt the circadian rhythm of astronauts, leading to degradation of the quality of their sleep. Many studies have been undertaken to evaluate the sleep patterns of astronauts. Although the light-dark transitions are of interest, the greatest sleep disruption has resulted from timeline pressures or ambient noise. ${ }^{3}$

\section{High vacuum}

A high vacuum exists outside the space shuttle and the International Space Station. ${ }^{4}$ The pressure inside both spacecraft is regulated to $101.34 \mathrm{kPa}$ (14.7 psi) and is equilibrated after docking and before hatch opening. NASA's suit for spacewalks (extravehicular mobility unit) is pressurized to $29.5 \mathrm{kPa}$ with $100 \%$ oxygen. The Russian Orlan spacesuit is pressurized to $40 \mathrm{kPa}$. The transition from ambient pressure to vacuum during airlock depressurization causes considerable decompression stress to spacewalking astronauts. Thus, before spacewalks, astronauts perform an oxygen pre-breathe protocol that reduces the level of nitrogen in the tissues. Astronauts are trained to recognize the symptoms of decompression sickness. Treatment protocols involve repressurization, $100 \%$ oxygen therapy and, if necessary, over-pressurization of the spacesuit by use of a bends treatment adaptor.

The risks associated with depressurization of a suit or spacecraft are partially mitigated by micrometeoroid shielding in the suit and spacecraft modules. However, in June 1997, there was rapid depressurization of the Spektr module of the Mir space station following a collision with a supply vehicle. The hatch between the modules was quickly closed to prevent depressurization of the station. This episode was a reminder of the harsh reality of living in the vacuum of space. found at lower altitudes. These pertubations briefly subject astronauts to higher fluxes of ionizing radiation.

The average total dose of radiation that a person on earth receives from natural land-based sources and medical procedures is less than 0.005 Sievert (Sv) per year. The standard radiation dose associated with a chest radiograph is $0.02 \mu \mathrm{Sv}$, while commercial aircraft travel is associated with exposure to $0.3-5.7 \mu \mathrm{Sv}$ per hour. At orbital altitudes near that of the International Space Station, the dose-equivalent to the astronauts is about $0.3 \mathrm{~Sv}$ per year. ${ }^{7}$

Astronaut who fly missions solely in low orbit around the earth are unlikely to receive a total dose of $1 \mathrm{~Sv}$ over their career. However, as the duration of space flights become longer and as destinations take us farther from earth, radiation doses will become higher. Astronauts participating in exploratory missions to Mars in the coming decades will receive an estimated round-trip dose of $1 \mathrm{~Sv}^{8}$ During these 2- to 3 -year missions, there is a good chance that at least 1 solar flare will occur, which could drastically increase their exposure to $5 \mathrm{~Sv}$.

Ionizing radiation can kill cells, damage genetic material and, in some instances, lead to cancer. The primary biologic effect of low and moderate doses of radiation is damage to DNA. The mechanisms that give rise to genetic mutation involve physical energy transfer, free radical formation and alteration of the molecular structure of DNA. ${ }^{6}$

Health risks from radiation exposure may be described in terms of short-term effects and long-term risks. The extent and severity of short-term effects is determined by the type and amount of exposure to radiation. Dose-related short-term effects range from nausea and vomiting to central nervous system damage and even death. Long-term risks include cataracts with lens doses of $>8 \mathrm{mSv}$ and potentially cancer. ${ }^{9}$ This increased risk of cancer is the principal concern for as- 
tronauts exposed to space radiation. The risk decreases with increasing age at exposure ${ }^{10}$ and persists after landing.

The goal of human space-flight programs is to continue the exploration and development of space while minimizing risks from exposure to ionizing radiation. Astronauts are regarded as radiation workers and follow the "as low as reasonably achievable" principles and guidelines, with radiation monitoring to document exposure. NASA and the other international partners have adopted the recommendations of the National Council on Radiation Protection about exposure to radiation during human space-flight activities. ${ }^{8}$

\section{Space debris}

Space debris has become a greater risk for space flights in low orbit in recent years. Micrometeoroids exist naturally in the solar system from breakups of comets and asteroids, and space debris is associated with increased frequency of space flight. This debris includes leftover satellites, broken-up rocket stages and even paint flakes from deteriorating spacecraft. Today, there are more than 12000 objects larger than $10 \mathrm{~cm}$ (softball size and larger) that are being tracked by ground-based sensors and catalogued. ${ }^{11}$ Smaller objects probably number in the hundreds of thousands.

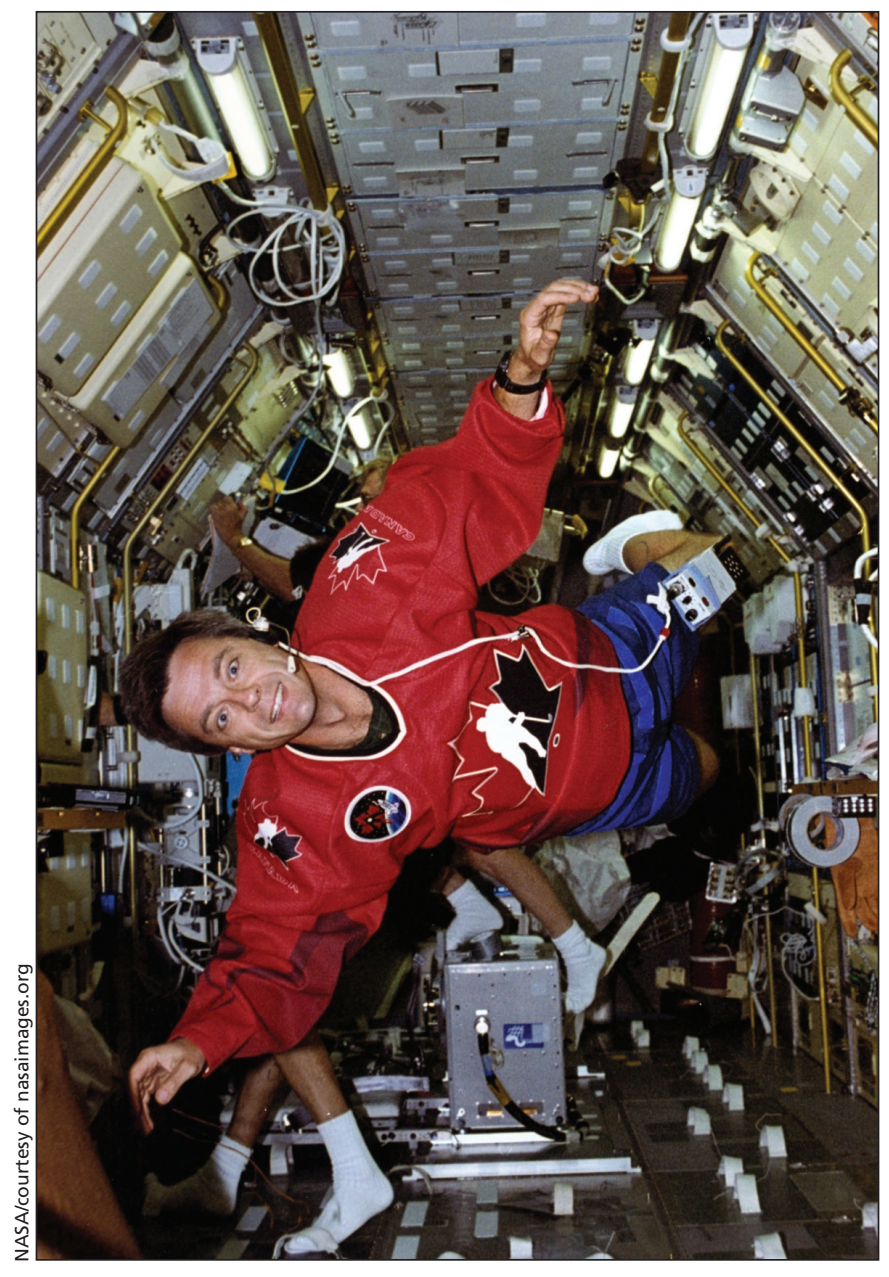

Robert Thirsk is pictured working in the spacelab during mission STS-78, his first flight, in 1996.
The consequences of collisions between spacecraft and a micrometeoroid or a piece of space debris can be catastrophic. Collisions take place at hyper-velocities of about $10 \mathrm{~km} / \mathrm{s}$ with dissipation of huge kinetic energies for very small particles. The impact of a collision of a $1 \mathrm{~kg}$ piece of space debris with the International Space Station has the same energy as a collision involving a $35000 \mathrm{~kg}$ tractor-trailer travelling at $190 \mathrm{~km} / \mathrm{h} .{ }^{12}$ Metal shielding can protect vulnerable parts of the space station against objects that are smaller than $1 \mathrm{~cm}$ diameter, while collision-avoidance manoeuvres have been taken by the shuttle and may be taken by the International Space Station to prevent collisions with larger pieces of debris.

Suit penetration from a micrometeoroid strike or an inadvertent puncture from a tool, wire or sharp edge is a risk associated with spacewalks. The 14 layers of material that make up the spacesuit include a layer of Kevlar to reduce the probability of suit penetration. To date, there have been no recorded cases of suit penetration from micrometeoroids. However, a tear to the outermost layer of a spacesuit glove from a sharp edge was noted on mission STS-118 in August 2007 , resulting in early termination of the spacewalk.

\section{Ionospheric plasma}

Spacecraft in low orbit around the earth have a complex interaction with ionospheric plasma. The solar arrays on the International Space Station operate at $160 \mathrm{~V}$, and the distribution system is at $120 \mathrm{~V} \mathrm{DC}$. The negative side of the power system is grounded to the structure of the space station, resulting in a large amount of energy stored in the structure at $-140 \mathrm{~V}$. High voltage solar arrays, coupled with the design and material properties of the International Space Station, can lead to detrimental interactions with the ionospheric plasma.

Two plasma contactor units have been placed on the International Space Station to provide a "ground wire" to prevent arc discharging. These devices emit a low-energy stream of electrons during spacewalks that reduces the buildup of electrical charge. ${ }^{13}$ As long as the plasma contactor units are functional, an astronaut floating freely during a spacewalk has no risk of exposure to arcing. However, the steel tethers used by astronauts to attach themselves to the structure of the space station and the exposed metallic surfaces of the spacesuit or tools used during the spacewalk are potential sources for arcing if both of the plasma contactor units were to fail during a spacewalk.

\section{Acoustic noise}

Spacecraft systems and experiments include fans, pumps and motors, which generate continuous noise. Acoustic levels at most locations on the International Space Station are close to 60 dBA (A-weighted decibels; similar to normal conversation level); however, certain areas of the space station are particularly noisy and are a potential source of hearing loss for astronauts. ${ }^{14}$

Elevated ambient noise can have a deleterious effect on communication between astronauts, and it may adversely affect performance through impaired concentration and distraction from tasks, in addition to disrupting sleep. Inadvertent alarms have woken astronauts from sleep, an issue of particular concern if it occurs before a critical task on the mission. 


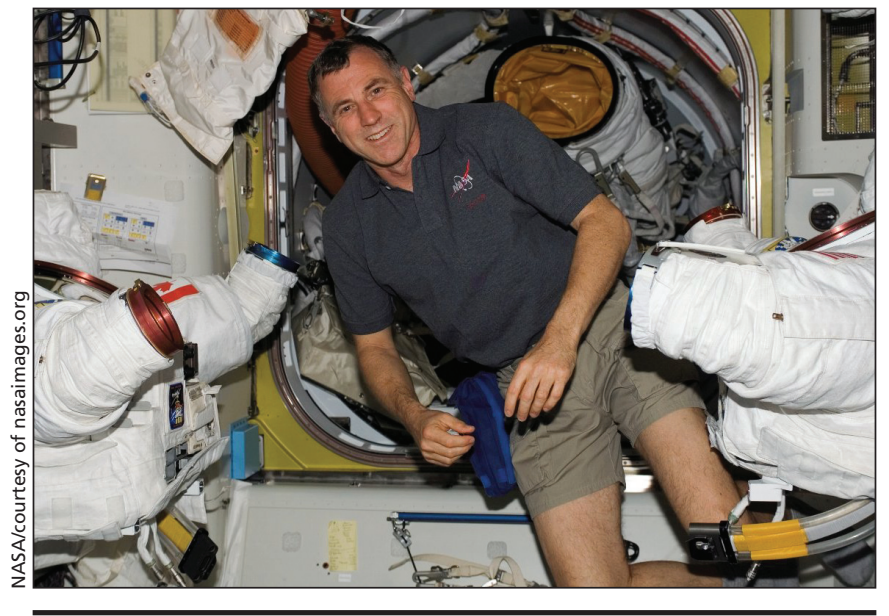

Dave Williams floats near the torso portions of 2 spacesuits in the Quest Airlock of the International Space Station.

\section{Microgravity}

The International Space Station is designed to serve as a research facility for low-gravity experimentation in fundamental science and technology development. Depending on which onboard systems are operating and the nature of crew activities, the acceleration environment on the station ranges from transient episodes of $0.01 \mathrm{~g}$ to quasi-steady levels below onemillionth of $1 g .{ }^{15}$

Perturbations in this environment occur during certain phases of orbital activity. Rendezvous and docking introduce transient accelerations that could be disruptive to certain experiments. In addition, on-board exercise devices could result in perturbations of the microgravity environment and are isolated (treadmill vibration isolation system) from adjacent structures. Rack isolation systems have also been developed to isolate critical experiments from transient vibrations and accelerations.

\section{Conclusion}

From a clinical perspective, the 2 major challenges associated with human space flight are the radiation effects and the physiologic consequences of living and working in a microgravity environment. All organ systems are affected in space to some degree where gravitational loading, hydrostatic pressure, convection, buoyancy and sedimentation do not exist. Consequently, microgravity is the most profound aspect of the space environment on human physiology.

A subsequent article in this series will provide an overview of the unique physiologic acclimations associated with human space flight and discuss the implications for the delivery of health care in partial and microgravitational environments.

\section{This article has been peer reviewed.}

Competing interests: David Williams was employed by the Canadian Space Agency from 1992 to 2008. During this time, he performed research into the space environment. None declared for Robert Thirsk, Andre Kuipers and Chiaki Mukai.

Contributors: All of the authors were involved in the drafting and revising of the article and approved the final version submitted for publication.

\section{REFERENCES}

1. National Space Biomedical Research Institute. Revised strategic plan. Houston (TX): The Institute; 2003. p. 6-7. Available: http://nsbri.tamu.edu/About/StrategicPlan.pdf (accessed 2009 Apr. 27).

2. Newman DJ. Life in extreme environments: How will humans perform on Mars? Gravit Space Biol Bull 2000;13:35-47.

3. Dijk DJ, Neri DF, Wyatt JK, et al. Sleep, performance, circadian rhythms, and light-dark cycles during two space shuttle flights. Am J Physiol Regul Integr Comp Physiol 2001;281:R1647-64.

4. Tennyson RC. Composites in space - Challenges and opportunities. Proceedings of the International Conference on Composite Materials (ICCM-10); 1995 Aug 14-18; Whistler (BC).

5. National Aeronautics and Space Administration. Space Radiation Analysis Group, Johnson Space Center. Washington (DC): The Administration; 2008. Available: http://srag.jsc.nasa.gov (accessed 2009 Apr.27).

6. Eckart P. Space flight life support and biospherics. Torrance (CA): Microcosm Press and Dordrecht, Netherlands: Kluwer Academic Publishers; 1999.

7. National Council on Radiation Protection and Measurements. Radiation protection guidance for activities in low-earth orbit. Report no. 132. ISBN 0-929600-65-7. Bethesda (MD): The Council; 2000.

8. National Council on Radiation Protection and Measurements. Guidance on radiation received in space activities. Report no. 98. ISBN 0-929600-04-5. Bethesda (MD): The Council; 1989.

9. Cucinotta FA, Manuel FK, Jones J, et al. Space radiation and cataracts in astronauts. Radiat Res 2001;156:460-66.

10. Nicogossian EA, Huntoon CL, Pool SL, editors. Space physiology and medicine Philadelphia (PA): Lea and Febiger; 1994. p. 167-93.

11. Koontz S, Suggs R, Schneider T, et al. Progress in spacecraft environment interactions: International Space Station development and operations. Proceedings of $26^{\text {th }}$ Annual International Space Development Conference. 2007 May 25-28; Dallas (TX).

12. Rodriguez HM, Liou JC. Orbital debris: past, present, and future. Proceedings of American Institute of Aeronautics and Astronautics (AIAA) Annual Technical Symposium. 2008 May 9; Houston (TX). Webster (TX): American Institute of Aeronautics and Astronautics; 2008.

13. Tribble AC. The space environment and its impact on spacecraft design. 31st American Institute of Aeronautics and Astronautics (AIAA), Aerospace Sciences Meeting and Exhibit. 1993 Jan 11-14; Reno (NV). Webster (TX): American Institute of Aeronautics and Astronautics; 1993. p. 491.

14. Goodman JR. International Space Station acoustics. J Acoust Soc Am 2000;108: 2475 .

15. Soares C, Mikatarian R, Schmidl R, et al. Natural and induced space environments effects on the International Space Station. Proceedings of the 56th International Astronautical Congress; 2005 Oct. 17-21; Fukuoka, Japan. IAC-05-B4.2.07

16. Wilson JW, Badavi FF, Kim MY, et al. Natural and induced environment in low earth orbit [technical report]. Washington (DC): National Aeronautics and Space Administration; 2002. Report no. NASA/TM-2002-211668.

17. DeLombard R, Hrovat K, Kelly E, et al. Microgravity environment on the International Space Station. Washington (DC): National Aeronautics and Space Administration; 2004. Report no. NASA/TM-2004-213039. Available: http://gltrs.grc.nasa .gov/reports/2004/TM-2004-213039.pdf (accessed 2009 Apr. 27).

Correspondence to: Dr. David Williams, Department of Surgery, McMaster University, clo St. Joseph's Healthcare Hamilton, 50 Charlton St. E, Hamilton ON L8N 4A6; fax 905 521-6197; willd@mcmaster.ca

While preparing this article, astronaut Dr. Robert Thirsk was getting ready for a 6-month stint on the International Space Station, the first long-duration mission by a Canadian. In addition to being the medical officer for the 6-member international crew, Dr. Thirsk will work as a robotics specialist, operating Canadarm2, and perform experiments on behalf of Canadian and international scientists. The launch was set for late May aboard a Russian Soyuz rocket from Baikonur, Kazakhstan.

In 1996, Robert Thirsk wrote a Special Report for CMAJ prior to his flight aboard the space shuttle Columbia. This report is available at www.cmaj.ca/cgi/content/full/154/12/1884/DC1 